\title{
Public lacks knowledge on chronic kidney disease: telephone survey
}

\author{
KM Chow *, CC Szeto, Bonnie CH Kwan, CB Leung, Philip KT Li
}

\section{A B S T R A C T}

Objectives: To examine knowledge of chronic kidney disease in the general public.

Design: Cross-sectional telephone survey.

Setting: Hong Kong.

Participants: Community-dwelling adults who spoke Chinese in Hong Kong.

Results: The response rate was $47.3 \%$ (516/1091) out of all subjects who were eligible to participate. The final survey population included 516 adults (55.6\% female), of whom over $80 \%$ had received a secondary level of education or higher. Close to $20 \%$ of the participants self-reported a diagnosis of hypertension. Few $(17.8 \%)$ realised the asymptomatic nature of chronic kidney disease. Less than half of these individuals identified hypertension (43.8\%) or

This article was published on 14 Mar 2014 at www.hkmj.org. diabetes $(44.0 \%)$ as risk factors of kidney disease. Awareness of high dietary sodium as a risk factor for chronic kidney disease was high (79.5\%).
Conclusions: The public in Hong Kong is poorly informed about chronic kidney disease, with major knowledge gaps regarding the influence of hypertension on kidney disease. We are concerned about the public's unawareness of hypertension being a risk factor for kidney disease. Future health education should target areas of knowledge deficits.

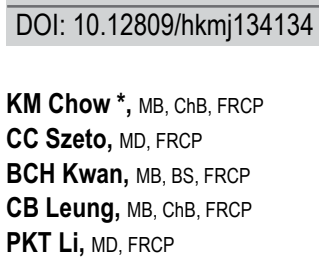

Department of Medicine and Therapeutics, The Chinese University of Hong Kong, Prince of Wales Hospital, Shatin, Hong Kong

* Corresponding author: Chow_Kai_Ming@alumni.cuhk.net

New knowledge added by this study

Despite the wealth of evidence for hypertension being a risk factor of chronic kidney disease, less than half the general public in Hong Kong are aware of the association.

- Only $17.8 \%$ of respondents in a telephone survey recognised the asymptomatic nature of chronic kidney disease.

Implications for clinical practice or policy

- There is an urgent need for better public education focused on risk factors of chronic kidney disease, so as to improve the chance of opportunistic screening for kidney disease.

\section{Introduction}

Several recent surveys have documented low levels of knowledge about chronic kidney disease among patients. ${ }^{1-3}$ In a US survey of almost 400 patients at all stages of chronic kidney disease not on dialysis, ${ }^{1}$ more than half reported no or little knowledge about the symptoms of kidney disease, or medications that can be harmful to the kidney. Furthermore, awareness of chronic kidney disease in the community is low, and limited knowledge about this disorder in the general public poses an even more significant hurdle in disease prevention. A large representative sample of Chinese adults yielded a $10.8 \%$ prevalence of chronic kidney disease, whereas only $12.5 \%$ of them were aware they had this condition. ${ }^{4}$

Data on general public knowledge on chronic kidney disease are essential to understanding knowledge gaps and formulating education programmes. Without knowing knowledge gaps, public health education programmes cannot be planned in a strategic manner. To examine knowledge on kidney disease and identify areas of misconception in the general population, we conducted a cross-sectional telephone survey in Hong Kong. We anticipated that assessment of knowledge gaps would be important to improve the public education and has the potential of preventing chronic kidney disease. ${ }^{5}$

\section{Methods}

Between 4 and 7 March 2013, we carried out a telephone survey of adults in Hong Kong. Respondents were required to be adults aged 18 years or older, and to speak Cantonese or Mandarin. The sampling method entailed selecting telephone numbers randomly from the latest Hong Kong 


\section{市民缺乏對慢性腎病的認識：電話調查研究}

周啟明、司徒卓俊、關清霞、梁誌邦、李錦滔

目的：探討一般市民對於慢性腎病的認識。

設計：橫斷面電話調查。

安排：香港。

參與者：香港懂華語的成年人。

結果：嘗試接觸的 1091 人中, 516 人願意參與電話調查訪問, 反應率 為 $47.3 \%$ 。參與調查的 516 名成人中, $55.6 \%$ 為女性, 其中超過八成 曾接受中學或以上的教育。接近兩成的被訪者透露有高血壓。少數人

$(17.8 \%)$ 知悉慢性腎病可以是毫無症狀的; 其中不到一半的人士確 認高血壓 $(43.8 \%)$ 和糖尿病 $(44.0 \%)$ 為腎病的危險因素。大部分受 訪人士 $(79.5 \%)$ 知道高鈉飲食是慢性腎病的其中一項危險因素。

結論：香港市民對慢性腎病的認識不足, 他們未能知悉高血壓對腎病 的影響。我們所關注的是市民大眾未能認識到高血壓是腎病的一項危 險因素。未來的健康教育應針對這方面的知識。
Residential Telephone Directories (both Chinese and English versions) as seed numbers. In order to include unpublished telephone numbers, the last two digits of the selected seed numbers were replaced by two new and random digits generated by computer. When telephone contact was established successfully with a target household, only a person aged 18 years or more was chosen for an interview. When there was more than one eligible subject in the household, only one was chosen for the survey (by convenience).

As a result, a total of 11600 telephone calls were made, and 2659 families were successfully contacted. Ineligible contacts included invalid lines, nonresidential lines, voice machines, facsimile numbers, and language problems. Of those successfully connected, 1383 cut the line before confirmation, 562 targeted persons refused the interview, 185 families had no eligible participant, and 13 were not interviewed because the target participants were not available. Finally, a total of 516 respondents were successfully interviewed, yielding a response rate of $47.3 \%$ (out of the 1091 eligible families contacted).

Trained interviewers from Hong Kong Institute of Asia-Pacific Studies administered the survey by telephone, and each interview lasted 10 minutes. Participants were asked close-ended questions on general knowledge about chronic kidney disease. The survey domains and instrument were developed to assess knowledge of the respondents on the general function of the kidneys, causes and symptoms of chronic kidney disease, and management and treatment of kidney disease. Some of the multiple-choice questions were refined and modified from a questionnaire previously tested in Singapore. ${ }^{2}$ Pre-testing of the questionnaire was carried out on members of the public through focus group discussions. The questionnaire was tested for face validity as well as content saturation. The finalised questionnaire was administered to

TABLE I. Baseline demographic characteristics

\begin{tabular}{|c|c|}
\hline Characteristic & $\begin{array}{c}\text { No. }(\%) \text { of } \\
\text { participants } \\
(n=516)\end{array}$ \\
\hline Women & $287(55.6)$ \\
\hline \multicolumn{2}{|l|}{ Age group (years) } \\
\hline $18-29$ & $90(17.4)$ \\
\hline $30-39$ & $72(14.0)$ \\
\hline $40-49$ & $95(18.4)$ \\
\hline $50-59$ & $126(24.4)$ \\
\hline$\geq 60$ & $131(25.4)$ \\
\hline Refused to answer & $2(0.4)$ \\
\hline \multicolumn{2}{|l|}{ Education level } \\
\hline Lower than kindergarten & $14(2.7)$ \\
\hline Primary school & $76(14.7)$ \\
\hline 1-3 Years in secondary school & $85(16.5)$ \\
\hline 4-7 Years in secondary school & $157(30.4)$ \\
\hline Tertiary education without degree & $56(10.9)$ \\
\hline Tertiary education with degree or above & $124(24.0)$ \\
\hline Refused to answer & $4(0.8)$ \\
\hline \multicolumn{2}{|l|}{ Personal history of medical condition* } \\
\hline Diabetes mellitus & $35(6.8)$ \\
\hline Hypertension & $98(19.0)$ \\
\hline Hyperlipidaemia & $67(13.0)$ \\
\hline Chronic kidney disease & $19(3.7)$ \\
\hline Cardiac disease & $19(3.7)$ \\
\hline Cerebrovascular disease & $8(1.6)$ \\
\hline None of the above & $323(62.6)$ \\
\hline Unable to answer & $31(6.0)$ \\
\hline Refused to answer & $2(0.4)$ \\
\hline \multicolumn{2}{|l|}{$\begin{array}{l}\text { Family history (first-degree relatives) of } \\
\text { medical condition* }\end{array}$} \\
\hline Diabetes mellitus & $150(29.1)$ \\
\hline Hypertension & $221(42.8)$ \\
\hline Hyperlipidaemia & $84(16.3)$ \\
\hline Chronic kidney disease & $49(9.5)$ \\
\hline Cardiac disease & $68(13.2)$ \\
\hline Cerebrovascular disease & $71(13.8)$ \\
\hline None of the above & $178(34.5)$ \\
\hline Unable to answer & $28(5.4)$ \\
\hline Refused to answer & $2(0.4)$ \\
\hline
\end{tabular}


patients at primary care public medical centres in persons with no known chronic kidney disease. ${ }^{2} \mathrm{We}$ also collected demographic information (age, sex, education level, and self-reported health conditions) from the respondents.

Statistical analyses were performed using the Statistical Package for the Social Sciences (Windows version 16.0; SPSS Inc, Chicago [IL], US). Numerical data were expressed as mean \pm standard deviation. Percentages were compared by means of Fisher's exact test or Chi squared test. A two-tailed $P$ value of $<0.05$ was regarded as statistically significant.

\section{Results}

Table 1 lists the characteristics of the respondents, who had a median age of 50 years. Over $80 \%$ of them had received a secondary or higher level of education. Only $3.7 \%(n=19)$ of the respondents were aware of any personal history of chronic kidney disease, and $19.0 \%(n=98)$ admitted they had hypertension. A family history of hypertension and diabetes was reported in $42.8 \%$ and $29.1 \%$ of the respondents, respectively.

Table 2 lists the answers to questions on the function of the kidneys and general knowledge on kidney disease. Only $27.9 \%$ of the respondents knew that only one kidney is needed for a human being to lead a normal life, although most (84.7\%) were aware of the kidney's function. Most respondents (79.5\%) listed high dietary sodium as a risk factor for chronic kidney disease, but hypertension and diabetes were selected less frequently. Less than half of the respondents knew that hypertension (43.8\%) and diabetes $(44.0 \%)$ can cause kidney disease, but $52.7 \%$ answered that frothy urine can be an early manifestation of kidney disease. However, only $17.8 \%$ correctly identified the asymptomatic nature of chronic kidney disease.

We further analysed factors that are associated with a lack of knowledge that hypertension can cause chronic kidney disease. There were no significant differences between groups in terms of age and gender. On the other hand, respondents with higher levels of education were more likely to self-report a personal or family history of hypertension and a personal history of diabetes mellitus (Table 3), and were more likely to know that hypertension is a cause of kidney disease. Similarly, a higher education level and a personal history of diabetes mellitus were associated with better knowledge about the causal relationship between diabetes and chronic kidney disease (Table 4).

Table 5 shows the perceived sequelae of chronic kidney disease. Overall, more than $80 \%$ of respondents said that kidney disease could be prevented, and could be controlled by medication. On the other hand, over $60 \%$ of them did not identify hypertension as a complication of chronic kidney
TABLE 2. Respondents' general knowledge and perception on kidneys, causes of kidney diseases, and symptoms that might progress to kidney failure

\begin{tabular}{|cc|}
\hline Questions & $\begin{array}{c}\text { No. (\%) of } \\
\text { participants } \\
(\mathbf{n}=516)\end{array}$ \\
\hline $\begin{array}{l}\text { No. of healthy kidney(s) needed to lead a } \\
\text { normal life }\end{array}$ \\
\hline 1 & $144(27.9)$ \\
\hline 2 & $316(61.2)$ \\
\hline 3 & $1(0.2)$ \\
\hline 4 & $2(0.4)$ \\
\hline 5 & $1(0.2)$ \\
\hline Do not know & $52(10.1)$
\end{tabular}

Function of kidney*

\begin{tabular}{|c|c|}
\hline To break down food & $32(6.2)$ \\
\hline $\begin{array}{l}\text { To produce substances that break down } \\
\text { fats }\end{array}$ & $38(7.4)$ \\
\hline To filter waste products in the blood & $437(84.7)$ \\
\hline Others & $3(0.6)$ \\
\hline Do not know & $33(6.4)$ \\
\hline
\end{tabular}

Perceived cause(s) of chronic kidney disease*

Drinking alcohol $272(52.7)$

Inadequate sleep 239 (46.3)

Taking too much salt $\quad 410(79.5)$

High blood pressure $226(43.8)$

Diabetes $227(44.0)$

Inherited condition $221(42.8)$

Others $6(1.2)$

Do not know 14 (2.7)

Perceived symptom(s) of early kidney disease that might progress to kidney failure*

Bubbles in the urine

$272(52.7)$

Yellow urine

$209(40.5)$

Frequent thirst

$211(40.9)$

Back pain 273 (52.9)

Blood in the urine $257(49.8)$

Yellow eyes $116(22.5)$

Without symptoms or complaints $92(17.8)$

Others $8(1.6)$

Do not know

$52(10.1)$

* The percentages do not total 100\% because more than one answer was permitted

disease. Furthermore, nearly half $(43.6 \%)$ of the subjects did not know the importance of checking the blood pressure in patients with chronic kidney disease, and less than a quarter (22.5\%) believed that chronic kidney disease can increase the risk of atherosclerosis. 
TABLE 3. Factors associated with the respondents' knowledge that hypertension can cause chronic kidney disease

\begin{tabular}{|c|c|c|c|}
\hline \multirow[t]{2}{*}{ Factors } & \multicolumn{2}{|c|}{ No. (\%) } & \multirow[t]{2}{*}{$P$ value } \\
\hline & $\begin{array}{c}\text { Participants who answered } \\
\text { correctly }(n=226)\end{array}$ & $\begin{array}{l}\text { Participants who answered } \\
\text { incorrectly }(n=290)\end{array}$ & \\
\hline Women & $127(56.2)$ & $160(55.2)$ & 0.54 \\
\hline Age group (years) ${ }^{\star}$ & & & 0.68 \\
\hline $18-29$ & $35(38.9)$ & $55(61.1)$ & \\
\hline $30-39$ & $32(44.4)$ & $40(55.6)$ & \\
\hline $40-49$ & $41(43.2)$ & $54(56.8)$ & \\
\hline $50-59$ & $63(50.0)$ & $63(50.0)$ & \\
\hline$\geq 60$ & $54(41.2)$ & 77 (58.8) & \\
\hline Refused to answer & $1(50.0)$ & $1(50.0)$ & \\
\hline Education level ${ }^{\star}$ & & & 0.031 \\
\hline Lower than kindergarten & $5(35.7)$ & $9(64.3)$ & \\
\hline Primary school & $26(34.2)$ & $50(65.8)$ & \\
\hline $1-3$ Years in secondary school & $33(38.8)$ & $52(61.2)$ & \\
\hline 4-7 Years in secondary school & $66(42.0)$ & $91(58.0)$ & \\
\hline Tertiary education without degree & $25(44.6)$ & $31(55.4)$ & \\
\hline Tertiary education with degree or above & $67(54.0)$ & $57(46.0)$ & \\
\hline Refused to answer & $4(100.0)$ & 0 & \\
\hline Self-reported history of hypertension & $51(22.6)$ & 47 (16.2) & 0.042 \\
\hline Self-reported history of diabetes mellitus & $25(11.1)$ & $10(3.4)$ & 0.001 \\
\hline Family history of hypertension & $111(49.1)$ & $110(37.9)$ & 0.004 \\
\hline Family history of diabetes mellitus & $73(32.3)$ & $77(26.6)$ & 0.096 \\
\hline
\end{tabular}

* The percentages refer to the row percentages

TABLE 4. Factors associated with the respondents' knowledge that diabetes mellitus can cause chronic kidney disease

\begin{tabular}{|c|c|c|c|}
\hline \multirow[t]{2}{*}{ Factors } & \multicolumn{2}{|c|}{ No. $(\%)$} & \multirow[t]{2}{*}{$P$ value } \\
\hline & $\begin{array}{l}\text { Participants who answered } \\
\text { correctly }(\mathrm{n}=227)\end{array}$ & $\begin{array}{l}\text { Participants who answered } \\
\text { incorrectly }(n=289)\end{array}$ & \\
\hline Women & $130(57.3)$ & $157(54.3)$ & 0.53 \\
\hline Age group (years) ${ }^{*}$ & & & 0.022 \\
\hline $18-29$ & $41(45.6)$ & $49(54.4)$ & \\
\hline $30-39$ & $21(29.2)$ & $51(70.8)$ & \\
\hline $40-49$ & $54(56.8)$ & $41(43.2)$ & \\
\hline $50-59$ & $55(43.7)$ & $71(56.3)$ & \\
\hline$\geq 60$ & $55(42.0)$ & $76(58.0)$ & \\
\hline Refused to answer & $1(50.0)$ & $1(50.0)$ & \\
\hline Education level* & & & 0.045 \\
\hline Lower than kindergarten & $5(35.7)$ & $9(64.3)$ & \\
\hline Primary school & $24(31.6)$ & $52(68.4)$ & \\
\hline 1-3 Years in secondary school & $31(36.5)$ & $54(63.5)$ & \\
\hline 4-7 Years in secondary school & $72(45.9)$ & $85(54.1)$ & \\
\hline Tertiary education without degree & $27(48.2)$ & $29(51.8)$ & \\
\hline Tertiary education with degree or above & $65(52.4)$ & $59(47.6)$ & \\
\hline Refused to answer & $3(75.0)$ & $1(25.0)$ & \\
\hline Self-reported history of hypertension & $49(21.6)$ & $49(17.0)$ & 0.21 \\
\hline Self-reported history of diabetes mellitus & $29(12.8)$ & $6(2.1)$ & $<0.001$ \\
\hline Family history of hypertension & $104(45.8)$ & $117(40.5)$ & 0.24 \\
\hline Family history of diabetes mellitus & 74 (32.6) & $76(26.3)$ & 0.12 \\
\hline
\end{tabular}

* The percentages refer to the row percentages 
TABLE 5. Questions on the care of kidney disease

\begin{tabular}{|c|c|}
\hline Questions & $\begin{array}{c}\text { No. }(\%) \text { of } \\
\text { participants } \\
(n=516)\end{array}$ \\
\hline \multicolumn{2}{|c|}{ Chronic kidney disease can be prevented } \\
\hline Agree & $455(88.2)$ \\
\hline Disagree & $39(7.6)$ \\
\hline Do not know & $22(4.3)$ \\
\hline \multicolumn{2}{|c|}{$\begin{array}{l}\text { Chronic kidney disease can be controlled by } \\
\text { medication }\end{array}$} \\
\hline Agree & $454(88.0)$ \\
\hline Disagree & $35(6.8)$ \\
\hline Do not know & $27(5.2)$ \\
\hline \multicolumn{2}{|c|}{$\begin{array}{l}\text { Chronic kidney disease can cause the } \\
\text { following condition(s) }\end{array}$} \\
\hline Kidney stone & $268(51.9)$ \\
\hline High blood pressure & $196(38.0)$ \\
\hline High lipid level & $131(25.4)$ \\
\hline Diabetes & $207(40.1)$ \\
\hline Atherosclerosis & $116(22.5)$ \\
\hline Others & $9(1.7)$ \\
\hline Do not know & $68(13.2)$ \\
\hline \multicolumn{2}{|c|}{$\begin{array}{l}\text { Patients with chronic kidney disease should } \\
\text { pay attention to* }\end{array}$} \\
\hline Urine test & $372(72.1)$ \\
\hline Blood sugar test & $259(50.2)$ \\
\hline Blood lipid test & $206(39.9)$ \\
\hline Blood pressure measurement & $291(56.4)$ \\
\hline Others & $3(0.6)$ \\
\hline Do not know & $41(7.9)$ \\
\hline
\end{tabular}

* The percentages do not total $100 \%$ because more than one answer was permitted

\section{Discussion}

The main findings from this survey define the key knowledge gaps concerning the kidney disease. In particular, the public in Hong Kong is unfamiliar with the relationship between hypertension and kidney disease. Almost four in five knew that high dietary sodium intake can be associated with kidney disease, but the risk of hypertension causing kidney disease was underestimated. Only $43.8 \%$ of respondents considered hypertension as a factor that increases the risk of kidney disease, and $43.6 \%$ did not perceive the need for patients with kidney disease to have blood pressure monitored. Another key issue was that close to $20 \%$ of the respondents self-reported a diagnosis of hypertension. Quantifying such knowledge deficit indicates that high blood pressure is relatively neglected and provides useful input for future public education.

Low public awareness of hypertension as a cause of kidney damage has been demonstrated in other national surveys. A cross-sectional survey of 1435 primary care patients without kidney disease in Singapore reported that only $51.2 \%$ knew that chronic kidney disease could be caused by diabetes, hypertension, and hereditary conditions. ${ }^{2}$ Overall, the public remains relatively unaware of the two leading causes of chronic kidney disease (hypertension and diabetes) in all developed and many developing countries. Similar to hypertension, the rising worldwide prevalence of diabetes and the lack of knowledge about its relationship with chronic kidney disease are of great concern. ${ }^{6}$ The AusDiab study involving a survey of 852 Australian subjects from the general population found an even lower level of understanding of hypertension; $25.7 \%$ of respondents reported poor diet as a cause of kidney disease but only $2.8 \%$ identified hypertension as risk factor. ${ }^{7}$ According to a cross-sectional survey of 2017 African Americans, 12.1\% knew that having hypertension was a risk factor for kidney disease. ${ }^{8} \mathrm{~A}$ strikingly prevailing theme among all these surveys (including ours) was the tendency of the public to name aspects of lifestyle instead of medical conditions as risk factors for kidney disease. In other words, there is relatively higher awareness of dietary risk factors for kidney disease compared with highrisk medical condition, notably hypertension. This was affirmed in a community-based qualitative exploratory analysis on kidney disease knowledge among rural populations in the US. ${ }^{9}$ Analysis of the audiotape scripts identified a representative theme: lifestyle choices, such as drinking sodas and diet, were routinely brought up as a means to explain the occurrence of kidney disease. ${ }^{9}$

More accurate and prioritised knowledge of kidney disease risk factors will lead to better disease awareness and increase chances of opportunistic screening. It is of concern that the general public underestimates the importance of blood pressure control. The most recent Global Burden of Disease Study launched by the World Bank and the World Health Organization announced that high blood pressure has shifted from the fourth to the top risk factor in terms of the global disability-adjusted life-years. ${ }^{10}$ Inability to consider hypertension as the risk factor for kidney disease implies that many subjects perceive themselves at lower risk of kidney disease, do not get screened, and have less concern for certain health behaviours. In fact, insufficient knowledge can drive the problem of antihypertensive medication non-adherence, which has recently been confirmed to confer an increased risk of end-stage renal disease. Using the Canadian health insurance databases of 185476 patients with hypertension, among those who were in possession of their prescribed medication, more than $80 \%$ of the time had a 33\% lower risk of end-stage renal disease. ${ }^{11}$ 
Targeting health care professionals is probably not the utmost concern, because only $3.4 \%$ of primary care physicians failed to recognise hypertension as a risk factor for chronic kidney disease according to a cross-sectional representative survey of primary care providers in the community. ${ }^{12}$ On the other hand, targeting public education to prevent asymptomatic renal disease should be explored. We have previously confirmed a high frequency of abnormal blood pressure readings and subclinical urinalysis abnormalities (17.4\%) in a screening programme of 1201 apparently healthy communitydwelling adults in Hong Kong. ${ }^{13}$ A successful public educational programme should therefore aim at better informing the asymptomatic nature of early chronic kidney disease, and address the risk factors such as hypertension. For this reason, the role of hypertension in kidney disease was chosen as the key message for World Kidney Day 2009. ${ }^{14}$

One important limitation of our survey was that individual-level data of subjects who declined the interview were missing. The fact that we could not compare the baseline characteristics of participants and those who declined raises the possibility of response bias. Response bias implies that the small percentage of subjects who responded could have differed systematically from the majority who did not answer telephone calls or cut the line before confirmation. Moreover, the sample of respondents in this residential telephone registry may not be generalised to other populations, such as those who mostly use mobile phones. Thus, requirement of a landline telephone in order to be sampled by the current random digit-dial telephone survey raised the possibility of non-coverage bias. Furthermore, our survey tool was not developed through experts in health literacy and psychometric analyses, and the questions were not field-tested and validated. We are aware of better constructed chronic kidney diseasespecific knowledge survey tools in other populations with known kidney disease. ${ }^{15}$ Future research to assess kidney disease knowledge in the Chinese community should follow similar developments to improve the reliability and validity of questionnaires. In addition, the diagnosis of hypertension and chronic kidney disease in our telephone survey respondents was not validated, instead it was based entirely on self-reporting.

\section{Conclusions}

The general public in Hong Kong did not recognise that the kidney is both a cause and victim of hypertension. Public health education efforts that target knowledge of kidney disease risk factors may help reduce the burden of kidney disease.

\section{Declaration}

No conflicts of interest were declared by authors.

\section{References}

1. Wright Nunes JA, Wallston KA, Eden SK, Shintani AK, Ikizier TA, Cavanaugh KL. Associations among perceived and objective disease knowledge and satisfaction with physician communication in patients with chronic kidney disease. Kidney Int 2011;80:1344-51.

2. Chow WL, Joshi VD, Tin AS, et al. Limited knowledge of chronic kidney disease among primary care patients-a cross-sectional survey. BMC Nephrol 2012;13:54.

3. Tan AU, Hoffman B, Rosas SE. Patient perception of risk factors associated with chronic kidney disease morbidity and mortality. Ethn Dis 2010;20:106-10.

4. Zhang L, Wang F, Wang L, et al. Prevalence of chronic kidney disease in China: a cross-sectional survey. Lancet 2012;379:815-22.

5. Collins AJ, Gilbertson DT, Snyder JJ, Chen SC, Foley RN. Chronic kidney disease awareness, screening and prevention: rationale for the design of a public education program. Nephrology (Carlton) 2010;15(Suppl 2):37-42.

6. Jha V, Garcia-Garcia G, Iseki K, et al. Chronic kidney disease: global dimension and perspectives. Lancet 2013;382:260-72.

7. White SL, Polkinghorne KR, Cass A, Shaw J, Atkins RC, Chadban SJ. Limited knowledge of kidney disease in a survey of AusDiab study participants. Med J Aust 2008;188:204-8.

8. Waterman AD, Browne T, Waterman BM, Gladstone EH, Hostetter T. Attitudes and behaviors of African Americans regarding early detection of kidney disease. Am J Kidney Dis 2008;51:554-62.

9. Jennette CE, Vupputuri S, Hogan SL, Shoham DA, Falk RJ, Harward DH. Community perspectives on kidney disease and health promotion from at-risk populations in rural North Carolina, USA. Rural Remote Health 2010;10:1388.

10. Murray CJ, Lopez AD. Measuring the global burden of disease. N Engl J Med 2013;369:448-57.

11. Roy L, White-Guay B, Dorais M, Dragomir A, Lessard $M$, Perreault S. Adherence to antihypertensive agents improves risk reduction of end-stage renal disease. Kidney Int 2013;84:570-7.

12. Lea JP, McClellan WM, Melcher C, Gladstone E, Hostetter T. CKD risk factors reported by primary care physicians: do guidelines make a difference? Am J Kidney Dis 2006;47:727.

13. Li PK, Kwan BC, Leung CB, et al. Prevalence of silent kidney disease in Hong Kong: the screening for Hong Kong Asymptomatic Renal Population and Evaluation (SHARE) program. Kidney Int Suppl 2005;94:S36-40.

14. Bakris GL, Ritz E. The message for World Kidney Day 2009: hypertension and kidney disease: a marriage that should be prevented. Nephrology (Carlton) 2009;14:49-51.

15. Wright JA, Wallston KA, Elasy TA, Ikizler TA, Cavanaugh KL. Development and results of a kidney disease knowledge survey given to patients with CKD. Am J Kidney Dis 2011;57:387-95. 